\title{
SYNTHESIS AND CHARACTERIZATION OF PCL/CALCINED BONE COMPOSITES
}

\author{
SHAOHUA WANG ${ }^{1}$, DONG MA ${ }^{1}$, YIPING HUANG ${ }^{1}$, CHENGLI YAO ${ }^{1}$, ANJIAN XIE ${ }^{2}$, YUHUA SHEN ${ }^{*}$ \\ ${ }^{I}$ School of Chemistry and Chemical Engineering, Anhui University, 3 Feixi Road, Hefei Anhui 230039,PR China \\ ${ }^{2}$ School of Physics and Materials Science, Anhui University, 3 Feixi Road, Hefei Anhui 230039,PR China
}

(Received: November 22, 2012 - Accepted: April 24, 2013)

\begin{abstract}
In this article, the hydroxyapatite and carbonate(HAC) nanoparticles were obtained by calcining the original pig bones, and the influence of different calcining temperature on morphology and size was investigated. Then, the polycaprolactone(PCL)/HAC composite materials were synthesized through in-situ polymerization with caprolactone $(\mathrm{CL})$ and HAC. The effects of different weight ratios of HAC to CL on the performance of composites was discussed, and the morphology and microstructure of obtained composite materials were characterized by transmission electron microscopy(TEM), Fourier transform infrared(FTIR) and (X-ray diffraction)XRD, etc. The results showed that HAC was uniformly dispersed in PCL matrix, and the composite material with HAC of 6 wt $\%$ was chosen for further application. This study provided a new way for synthesizing PCL/HAC materials that could be used for repairing and substituting for human damaged bone, which is significant in the theory and practice of bio-medicine.
\end{abstract}

Keywords: Calcined bone particles; Polycaprolactone; Hydroxyapatite; Composite.

\section{INTRODUCTION}

Biomaterials play a dramatically important role in tissue engineering, which is aimed to provide replacements and help to repair the damaged or lost tissues and organs as a consequence of disease, aging or accident ${ }^{1}$. In order to meet multi-requirements of clinical applications, it is necessary to develop multi-component and multistructure biomaterials, which could combine the property advantages of included elements, i.e. mechanical properties, rate of biodegradation and bioactive function. This design provides new possibility in biomedical applications as new biomaterials.

The human bone contains hydroxyapatite(HA) and carbonate etc. Especially HA is widely used as bone implant materials in clinics in either sintered block or granular forms due to its excellent osteoconductivity ${ }^{2,3}$. However, the mechanical properties and biodegradability of the application forms have some limitations. Thus in recent years, many studies on HA focus on its composites with organic polymers, especially those possessing biodegradability ${ }^{4-11}$. The polymeric parts are metabolized and excreted, and the ceramic constituents are assimilated in the body. The brittleness of HA ceramics is also improved by mixing with tough organic polymers.

PCL is aliphatic, biodegradable polymer which is able to hydrolytic and enzymatic cleavage along polymer chains and is widely used for medical applications, pharmaceutical controlled release systems and in biodegradable packaging materials ${ }^{12}$.

So far, the papers about preparation of $\mathrm{PCL} / \mathrm{HA}$ composite materials have been reported ${ }^{13-17}$. However, PCL/HA composite materials were mostly prepared by blend ${ }^{18-20}$, in the process of which HA were produced through hydrothermal synthesis ${ }^{21}$ or sol-gel ${ }^{22}$, etc. To the best of our knowledge, no work was reported about the synthesis of composites of PCL and HAC which obtained by calcining original pig bone. The preparation of HAC is very convenient for its simple source of raw materials. Also, HA particles obtained coexist with traces of calcium carbonate, etc., which are more similar to the inorganic components of human bones.

Here, we first report the synthesis of PCL/HAC composites via in-situ polymerization. The properties of composites also investigated. These prepared PCL/HAC composites may have better prospect application in repairing and replanting biomaterial.

\section{EXPERIMENTAL}

2.1. Chemicals: Caprolactone (CL) was purchased from Aldrich. alcohol, stannous caprylate, toluene, tetrahydrofuran (THF), etc. All agents and solvents used in this work were of analytic reagent (AR) grade. They were used without further purification. Pig bone was purchased from farmer's market.

2.2. Instruments: Fourier transform infrared (FT-IR) spectra were recorded on a Nexus 870 Fourier transform infrared spectroscopy (American Nicolet Co.), transmission electron microscopy (TEM) experiments were performed using a JEM-100SX microscope operated at $100 \mathrm{kV}$ (Japan JEOL Co.), X-ray diffraction (XRD) results were recorded on a $\mathrm{D} / \mathrm{max}$-cA X-ray diffractometer (Japan Rigaku Co.) with a scan speed of $10^{\circ}(2 \theta) / \mathrm{min}$ and a scan step of 0.020 . Thermal properties of nanocomposite materials were recorded by Pyrir-1 differential scanning calorimetry (DSC) and Pyrir-1 thermo-gravimetric analysis (TGA) (American Perkin-Elmer Co.). The size distributions of HAC were recorded by Zetasizer 3000HSA Laser Particle Sizer (U.K. Malvern Co.).

2.3. Preparation of HAC and PCL/HAC composite materials: Firstly, the pig bone was boiled in distilled water for $12 \mathrm{~h}$. After dried, the HAC were obtained from calcined bone at different temperature with different time. CL monomer and as-prepared HAC (the content of HAC were $3 \mathrm{wt} \%, 6 \mathrm{wt} \%$ and 9 $\mathrm{wt} \%$, respectively) were mixed and then ultrasonically dispersed. After added in the four neck flask, the mixture was heated with nitrogen prevention. The stannous caprylate was added into the system when the temperature of mixture reached $150^{\circ} \mathrm{C}$. Then the temperature of system was rise to $170{ }^{\circ} \mathrm{C}$ and kept it for $1.5 \mathrm{~h}$. After the reaction finished, the composite materials were dissolved in THF and then dried in a vacuum drying box.

2.4. Principle of in-situ polymerization of PCL/HAC composites: The synthesis principle of PCL/HAC composite by in-situ polymerization is shown in reaction equation (1):

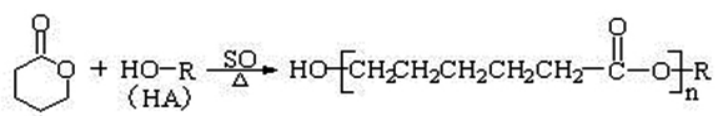

The hydroxyl groups on the surface of HA (HO-R) in HAC were surfacegrafted with PCL by ring-opening polymerization of CL, which inhibited the growth of PCL molecules.

\section{RESULTS AND DISCUSSION}

Fig. 1 displays the size distributions of HAC prepared by calcining bone. In Fig. 1a, HAC was prepared at different treatment temperature $\left(600^{\circ} \mathrm{C}, 800\right.$ ${ }^{\circ} \mathrm{C}, 900{ }^{\circ} \mathrm{C}, 1000{ }^{\circ} \mathrm{C}$ ) for $2 \mathrm{~h}$, respectively. Larger HAC nanoparticles were obtained at $600{ }^{\circ} \mathrm{C}$ (red line), their diameter are mainly concentrated at 500 $\mathrm{nm}$. HAC with wide distribution $\left(100-1500 \mathrm{~nm}\right.$ ) were received at $800^{\circ} \mathrm{C}$ (green line) and $1000^{\circ} \mathrm{C}$ (black line) are shown in Fig. 1a. It shows small size and concentrated distribution $(190 \mathrm{~nm})$ of HAC obtained at $900{ }^{\circ} \mathrm{C}$ (blue line). It's concluded that the $900^{\circ} \mathrm{C}$ is a optimal calcining temperature for the preparation of uniform HAC. Fig. 1b shows the size distribution of HAC obtained from calcined bone at $900^{\circ} \mathrm{C}$ with different time $(1 \mathrm{~h}, 3 \mathrm{~h})$. Compared with Fig. 1a (blue line) obtained for $2 \mathrm{~h}$, the HAC achieved with a wide distribution at $900{ }^{\circ} \mathrm{C}$ for $1 \mathrm{~h}$ (black line) and $3 \mathrm{~h}$ (red line). The average diameters of HAC are increased. It is demonstrated that the optimal calcined time of pig bone at $900{ }^{\circ} \mathrm{C}$ for the preparation of HAC is $2 \mathrm{~h}$. So the HAC obtained from calcined bone at $900{ }^{\circ} \mathrm{C}$ with $2 \mathrm{~h}$ was chosen in the following preparation of PCL/HAC composites. 

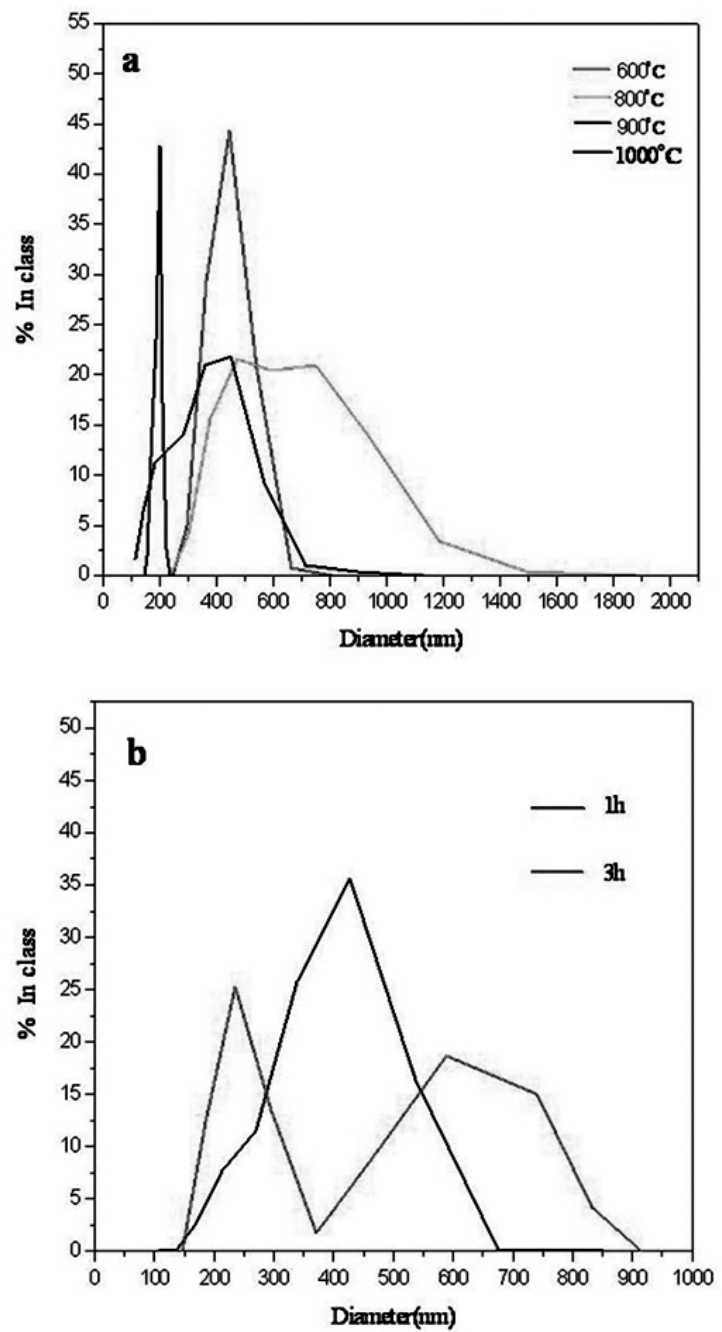

Fig. 1 Size distribution of HAC obtained from calcined bone at different treatment temperature and time. (a) different temperature for $2 \mathrm{~h}$; (b) different time at $900{ }^{\circ} \mathrm{C}$
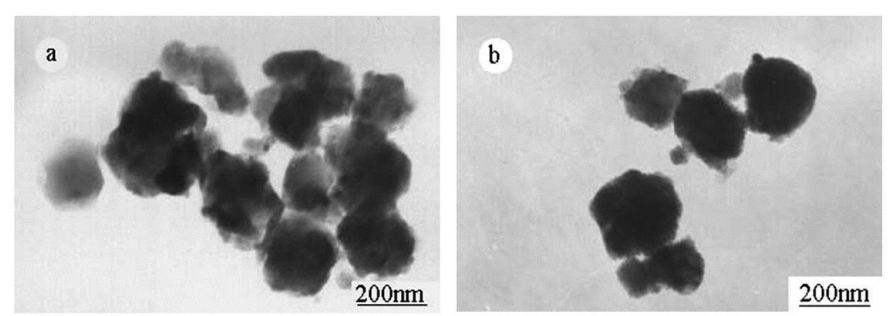

Fig. 2 TEM images of $\mathrm{HAC}$ obtained from calcined bone at $900{ }^{\circ} \mathrm{C}$ for $2 \mathrm{~h}$

TEM images of $\mathrm{HAC}$ obtained from calcined bone at $900{ }^{\circ} \mathrm{C}$ for $2 \mathrm{~h}$ are shown in Fig. 2. From the images, the spherical HAC were produced from calcined bone, and the average size of HAC was $190 \mathrm{~nm}$. The result corresponds to the size distributions of Fig. 1a (blue line).
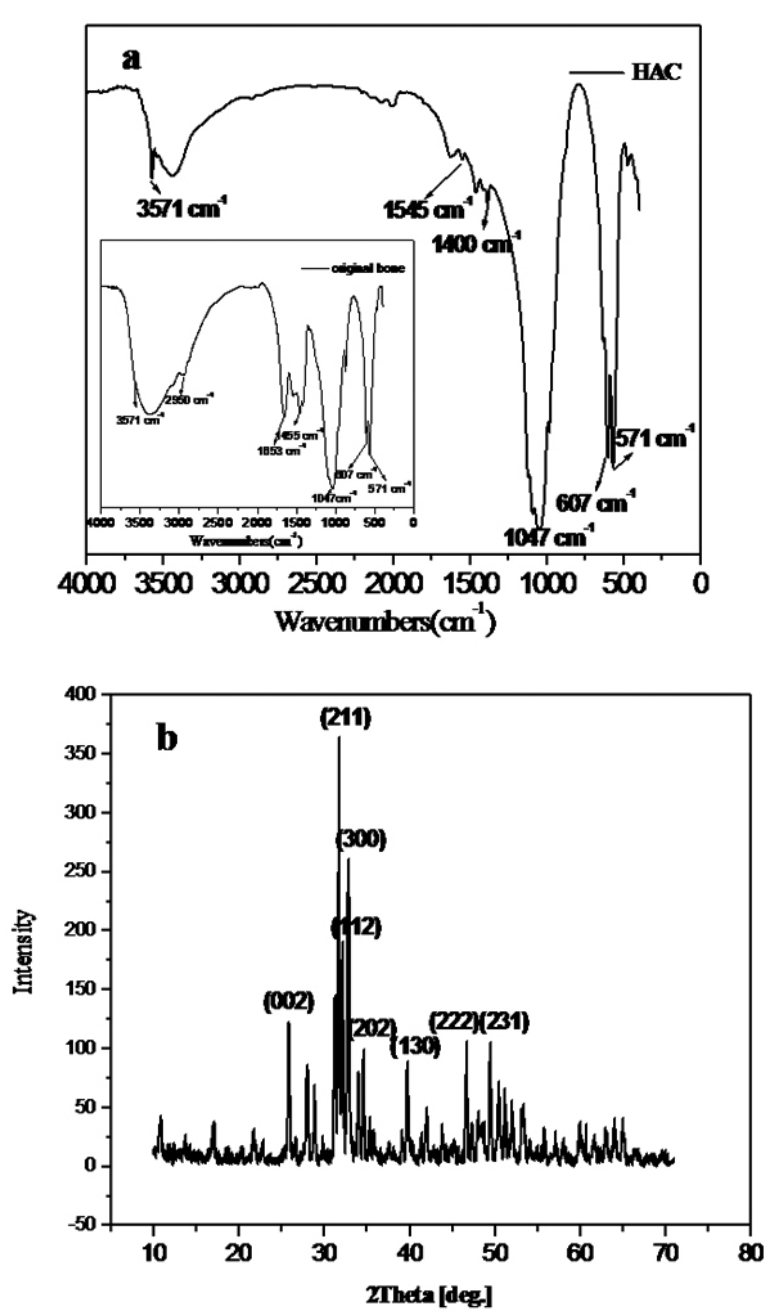

Fig. 3 FT-IR spectrum and XRD pattern of HAC obtained at $900{ }^{\circ} \mathrm{C}$ for 2 $\mathrm{h}$, Inset shows the FTIR spectrum of original bone. (a) FT-IR spectrum of HAC obtained at $900^{\circ} \mathrm{C}$ for $2 \mathrm{~h}$; (b) XRD pattern of HAC obtained at $900{ }^{\circ} \mathrm{C}$ for $2 \mathrm{~h}$

Fig. 3a presents FTIR spectrum of HAC obtained at $900{ }^{\circ} \mathrm{C}$ with $2 \mathrm{~h}$. It is observed that the bands appearing at $1047 \mathrm{~cm}^{-1}$ (P-O stretching vibration peak), $607 \mathrm{~cm}^{-1}$ and $571 \mathrm{~cm}^{-1}$ (P-O bending vibration peak) correspond to $\mathrm{HA}^{23}$. We can further see that, O-H stretching vibration peak is observed at 3571 $\mathrm{cm}^{-1}$ in Fig. 3a, and the same in the original bone shown in inset due to the presence of water. Through the comparison of the HAC FTIR spectrum and the inset of original bone FTIR spectrum, the C-H $\left(2950 \mathrm{~cm}^{-1}\right)$ absorption peak disappeared in HAC, it indicates that the organism of bone was burned out. In addition, it can be seen that the bands pertain to the $\mathrm{CO}_{3}{ }^{2-}$ functional group at 1545 (A-type) and $1400 \mathrm{~cm}^{-1}$ (B-type), indicating the substitution of $\mathrm{CO}_{3}{ }^{2-}$-ions into the $\mathrm{HA}^{24}$ in the original bone and HAC. It proves that $\mathrm{HAC}$ has a closer chemical component with that of biominerals of human calcified tissue. Fig. $3 \mathrm{~b}$ shows XRD pattern of HAC. The peaks at $2 \theta$ values of $25.88^{\circ}, 31.74^{\circ}$, $32.87^{\circ}, 34.05^{\circ}, 39.76^{\circ}, 46.66^{\circ}$, and $49.46^{\circ}$ are consistent with the $(002)$, (211), (300), (202), (130), (222), and (230) Bragg reflections of HA in HAC, respectively. A diffraction peak at $37.5^{\circ}$ belonged to $\mathrm{CaO}$ is observed ${ }^{25}$. Some miscellaneous peaks could be found in Fig. $3 \mathrm{~b}$ such as at $29.63^{\circ}$ and $31.32^{\circ}$ are assigned to $\mathrm{CaCO}_{3}$ and $\mathrm{Ca}_{3}\left(\mathrm{PO}_{4}\right)_{2}$. It could be concluded that a small quantity of calcium carbonate and calcium phosphate were obtained, and the HA is a main inorganic component of HAC. 

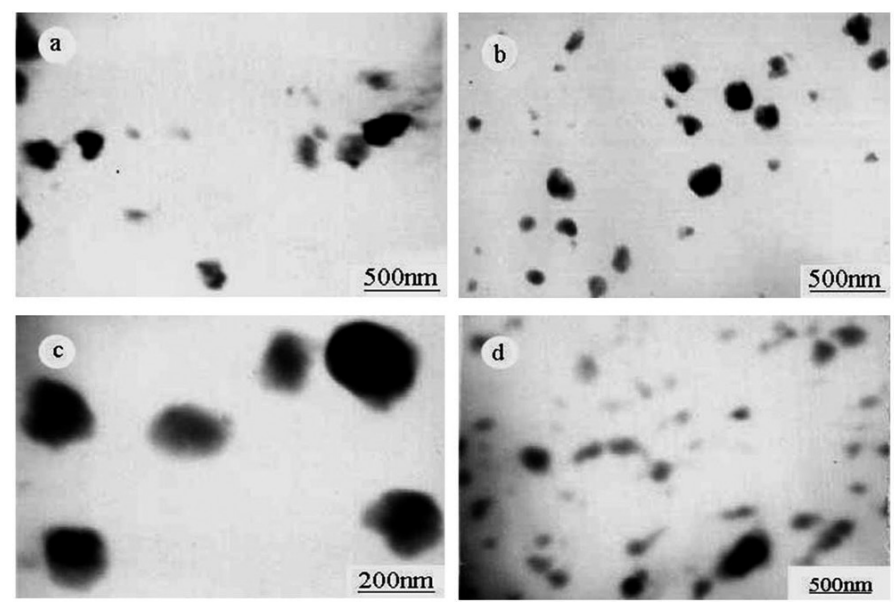

Fig. 4 TEM images of PCL/HAC composites contained different weight of HAC. (a) 3 wt \%; (b, c) $6 \mathrm{wt} \%$; (d) 9 wt \%

Fig. 4 displays the morphology of PCL/HAC composite materials with different weight of HAC from $3 \mathrm{wt} \%$ to $9 \mathrm{wt} \%$. Many spherical particles of the $\mathrm{PCL} / \mathrm{HAC}$ composite with the size of 100-250 nm are found. Among them, the content $6 \mathrm{wt} \%$ of HAC composite dispersed orderly. A clearly TEM image of the obtained PCL/HAC composite materials core-shell microspheres (Fig. 4c) shown that the dark HAC spherical particles are individually coated with a gray PCL shell with a thickness about $20-50 \mathrm{~nm}$. The images confirm the dispersion of HAC in the PCL matrix.
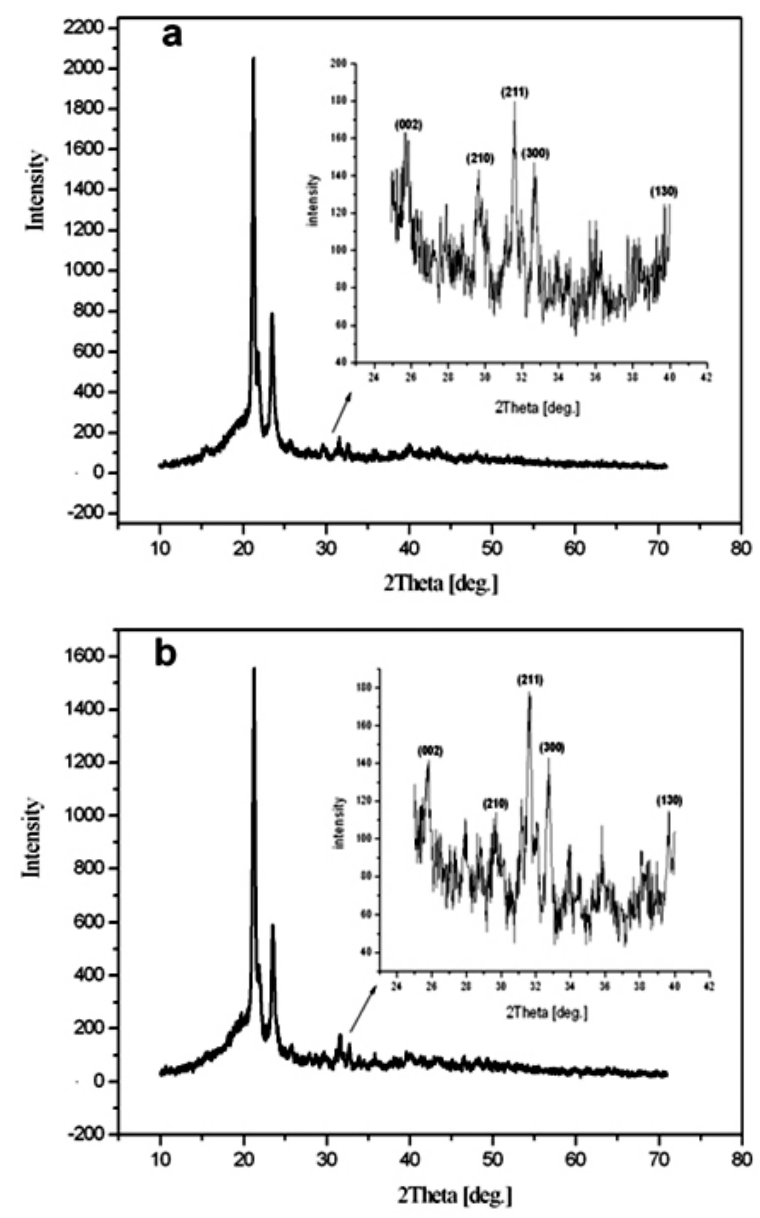
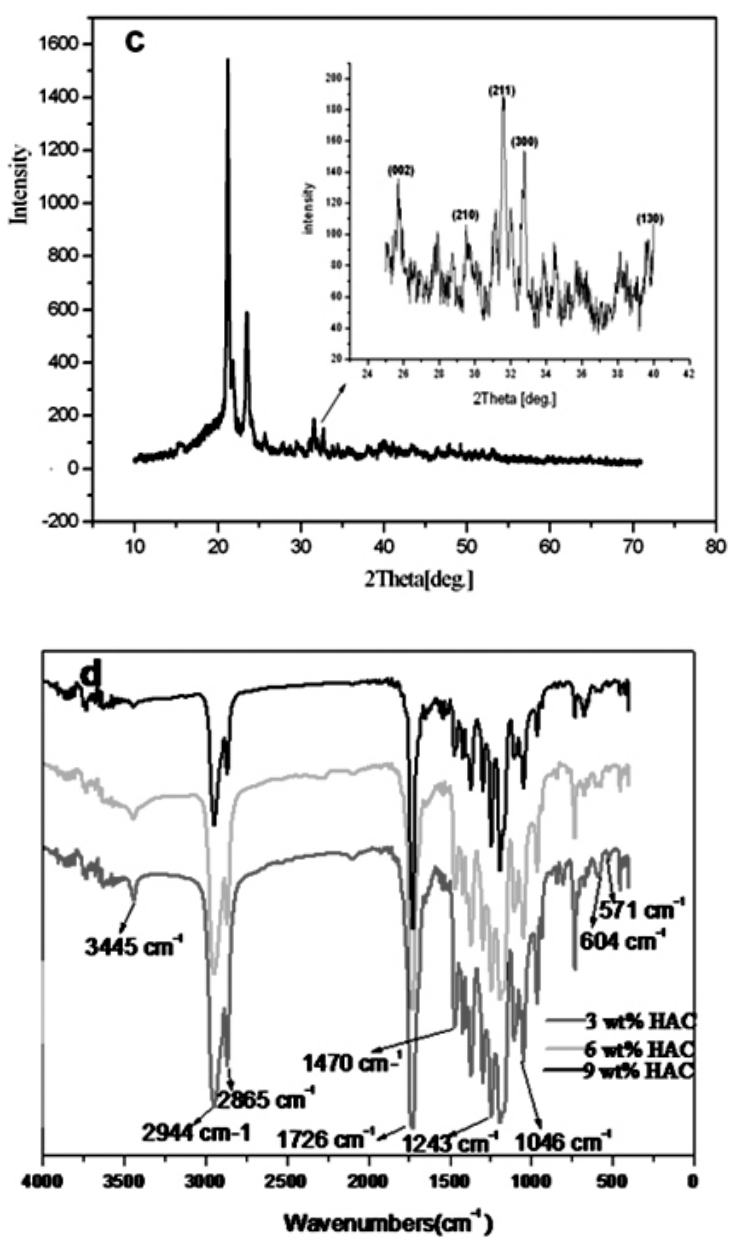

Fig. 5 XRD patterns and FT-IR spectrum of PCL/HAC composites containing different weight of HAC: (a) XRD pattern of PCL/HAC composites containing $3 \mathrm{wt} \% \mathrm{HAC}$; (b) XRD pattern of PCL/HAC composites containing $6 \mathrm{wt} \% \mathrm{HAC}$; (c) XRD pattern of PCL/HAC composites containing $9 \mathrm{wt} \%$ HAC; (d) FT-IR spectrum of PCL/HAC composites containing different weight of HAC

Fig. 5a, b and $\mathrm{c}$ give XRD patterns of PCL/HAC composite materials with different weight of HAC, respectively. As see from XRD patterns, the corresponding main strong peaks which belong to the diffraction of PCL are located at $21.28^{\circ}$ and $23.5^{\circ}$. But the peaks of HA are weaker because the content of HAC in composite materials is lower. Compared the inserts of Fig. 5a, b, c with Fig. 3b, the location of diffraction peaks are basically same, suggesting three groups of composite materials all contain HA. Fig. 5d demonstrates FTIR spectra of PCL/HAC composite materials containing different weight of HAC. The FT-IR spectra of three products are similar. The C-H stretching vibration peaks located at $2944 \mathrm{~cm}^{-1}, 2865 \mathrm{~cm}^{-1}$, and $1243 \mathrm{~cm}^{-1}$, meanwhile the $\mathrm{C}-\mathrm{O}$ stretching vibration and $\mathrm{C}-\mathrm{H}$ bending vibration peaks at $1726 \mathrm{~cm}^{-1}$ and $1470 \mathrm{~cm}^{-1}$ indicate the formation of PCL. The stretching bands shown at 3445 $\mathrm{cm}^{-1}$ (OH end groups), together with $571 \mathrm{~cm}^{-1}, 604 \mathrm{~cm}^{-1}$ and $1046 \mathrm{~cm}^{-1}$ are due to the presence of HA in HAC. This is further proved and validated that the three groups of PCL/HAC composites were successfully synthesized via in-situ polymerization of $\mathrm{CL}$ and HAC. 

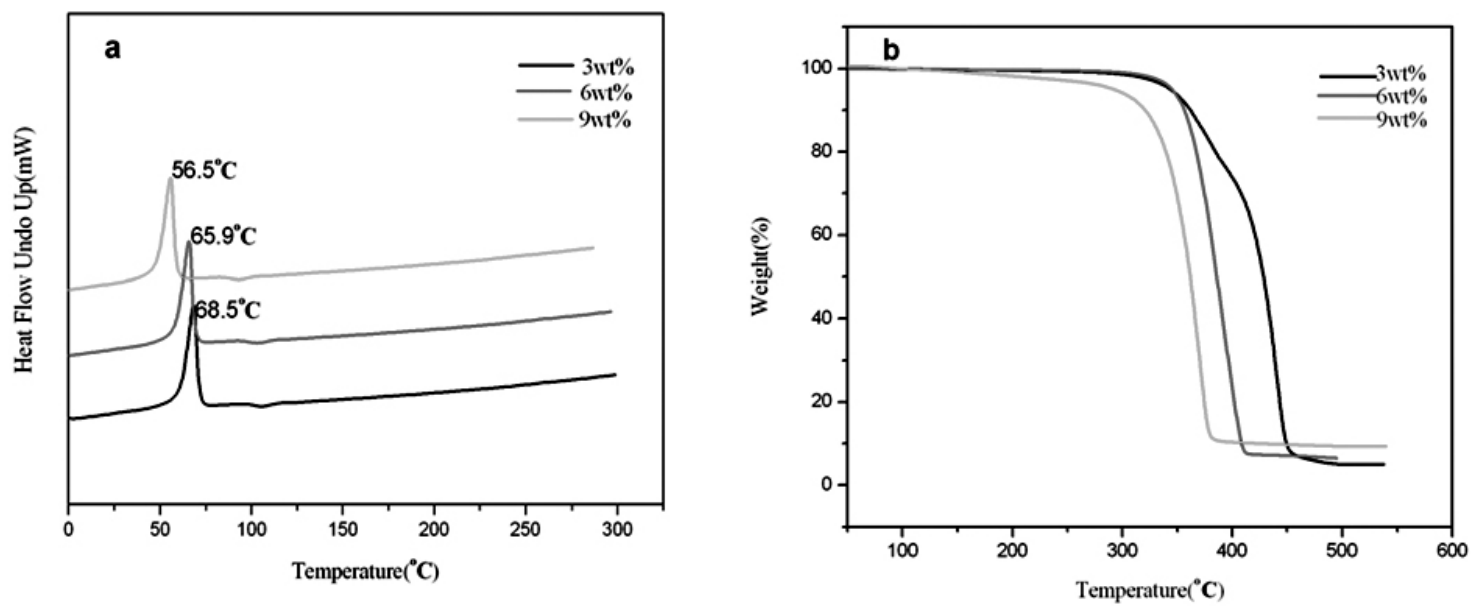

Fig. 6 DSC and TGA curves of PCL/HAC composites containing different weight of HAC. (a) DSC curves; (b) TGA curves.

Fig. 6 shows DSC and TGA curves of PCL/HAC composites containing different weight of HAC. From Fig. 6a, it can be seen clearly that the melting temperature of PCL decreased obviously with increasing weight of HAC (the melting temperature of pure PCL is $56.1{ }^{\circ} \mathrm{C}$ ), which suggested the crystal perfection and grain size of PCL were affected by HAC because that increasing weight of HAC can decline crystal perfection of PCL and inhibit growth of PCL molecules. As the decrease of molecular weight of composite materials, the grain size of PCL and the melting temperature of PCL/HAC composite materials compared with pure PCL crystalline was decreased. Moreover, TGA curves of PCL/HAC composites in the air atmosphere from room temperature to $550{ }^{\circ} \mathrm{C}$ are shown in Fig. 6 b. The thermal degradation temperature of PCL/ $\mathrm{HAC}$ composite materials concentrated from $300{ }^{\circ} \mathrm{C}$ to $500{ }^{\circ} \mathrm{C}$. The initial decomposed temperature of composites declined gradually with increasing the weight of HAC.
In Table 1, the maximum load, tension strength, elastic modulus yield strength and breaking elongation rate of $\mathrm{PCL} / \mathrm{HAC}$ composite materials decreased gradually with increasing the weight of HAC (Sample I $>$ II $>$ III). It could be concluded that the mechanical properties of composite materials with $\mathrm{HAC}$ of $3 \mathrm{wt} \%$ is best for the growth inhibition of PCL molecules, which was enhanced by increasing the hydroxyl groups of HA in HAC, resulting in decrease of molecular weight of composite materials, and declining the mechanical properties of composite material. So the higher intensity and rigidity of composite materials could be produced by decreasing the weight of HAC. However, the component of composite materials with lower weight of HAC would further different from that of human bone. The mechanical properties of composite material with HAC of $6 \mathrm{wt} \%$ are closer to that of composite material with $\mathrm{HAC}$ of $3 \mathrm{wt} \%$, so the comprehensive performance of composite material with HAC of $6 \mathrm{wt} \%$ would choose for further application.

Table 1 Tensile stress-strain data of PCL/HAC composites with different weight of HAC.

Sample I $3 \mathrm{wt} \%$

Sample II $6 \mathrm{wt} \%$

Sample III $9 \mathrm{wt} \%$

\begin{tabular}{|c|c|c|c|c|c|c|}
\hline Sample & $\begin{array}{c}\text { Cross section } \\
\left(\mathrm{mm}^{2}\right)\end{array}$ & $\begin{array}{c}\text { Maximum } \\
\text { load }(\mathrm{N})\end{array}$ & $\begin{array}{c}\text { Tension } \\
\text { strength }(\mathrm{MPa})\end{array}$ & $\begin{array}{c}\text { Elastic } \\
\text { modulus (MPa) }\end{array}$ & $\begin{array}{c}\text { Yield } \\
\text { strength (MPa) }\end{array}$ & $\begin{array}{c}\text { Breaking elongation } \\
\text { rate }(\%)\end{array}$ \\
\hline I & 13.38 & 261.33 & 19.53 & 2106.1 & 19.50 & 688.72 \\
\hline II & 13.20 & 254.89 & 19.31 & 1656.9 & 19.31 & 517.35 \\
\hline III & 9.00 & 104.63 & 11.63 & 453.5 & 0.00 & 0.63 \\
\hline
\end{tabular}

\section{CONCLUSIONS}

The HAC were obtained by calcining the natural pig bone in this work. Then, the PCL/HAC composite materials were synthesized through in situ polymerization of CL and produced HAC. And the morphology and microstructure of obtained HAC and composites were characterized by TEM images, FT-IR spectra and XRD patterns, etc. The results show that smaller size $(190 \mathrm{~nm})$ and uniform distribution of HAC were obtained by calcining bone at $900^{\circ} \mathrm{C}$ for $2 \mathrm{~h}$. HAC was uniformly dispersed in PCL matrix. The molecular weight of PCL in composites and the mechanical properties of $\mathrm{PCL} / \mathrm{HAC}$ decreased with the weight percentage of HAC increases. Finally, the comprehensive performance of composite material with HAC of $6 \mathrm{wt} \%$ is better. The study provides a new way to synthesize repairing and substituting materials for human damaged bone.

\section{ACKNOWLEDGEMENTS}

This work is supported by the National Nature Science Foundation of China (91022032, 21171001, 50973001 and 21173001), the Important Project of Anhui Provincial Education Department (ZD2007004-1), Key Laboratory of Environment-friendly Polymer Materials of Anhui Province.

\section{REFERENCES}

1. S.S. Kim, M. Sun Park, O. Jeon, C. Yong Choi.et al, Biomaterial. 27, 1399, (2006)

2. N. Fukui, T. Sato, Y. Kuboki, and Aoki, H, Bio-med Mater Eng. 18, 25, (2008)

3. S.E. Petricca, K.G. Marra, and Kumta, P.N. Acta Biomater. 2, 277, (2006)

4. P. Cerrai, G. Guerra, M. Tricoli, A. Krajewski, et al, J Mater Sci-Mater M. 10, 283, (1999)

5. N. Ignjatovic, S. Tomic, M. Dakic, et al, Biomaterials. 20, 809, (1999)

6. S. Jin, and K. Gonsalves, J Mater Sci-Mater M. 10, 363, (1999)

7. M. Kikuchi, Y. Suetsugu, J. Tanaka, and Akao, M, J Mater Sci-Mater M. 8, 361, (1997)

8. Q. Liu, J.R. Wijn, D. Bakker, et al. J Mater Sci-Mater M. 7, 551, (1996)

9. Y. Shikinami, and M. Okuno, Biomaterials. 20, 859, (1999)

10. C. Verheyen, J. De Wijn,C. Van Blitterswijk, et al, J Biomed Mater Res A. 26, 1277, (1992)

11. C. Verheyen, C. Klein, J.M.A. Blieck-Hogervorst, J Mater Sci-Mater M. 
4, 58, (1993)

12. P.B. Messersmith, and E.P. Giannelis, J Polym Sci Pol Chem. 33,1047, (1995)

13. M. Azevedo, R. Reis, M. Claase, et al, J Mater Sci-Mater M. 14, 103 , (2003)

14. S.C. Rizzi, D. Heath, A. Coombes, et al, J Biomed Mater Res A. 55, 475, (2001)

15. A. Salerno, S. Zeppetelli, E. Di Maio, et al, Biotechnol Bioeng. 108, 963 , (2011)

16. S. Scaglione, E. Lazzarini, C. Ilengo, J Tissue Eng Regen M. 4, 505, (2010)

17. L. Shor, E. Yildirim, S. Güçeri, W. Sun Precision Extruding Deposition for Freeform Fabrication of PCL and PCL-HA Tissue Scaffolds, Springer New York, Springer-Verlag New York, 2010.

18. D. Choi, K.G. Marra, and P.N. Kumta, Mater Res Bull. 39, 417, (2004)

19. J. Hao, M. Yuan, and X. Deng, J Appl Polym Sci. 86, 676, (2002)

20. H.W. Kim, J.C. Knowles, and H.E. Kim, Biomaterials. 25, 1279, (2004)

21. Y. Wang, S. Zhang, K. Wei, et al, Mater Lett. 60, 1484, (2006)

22. D.M. Liu, T. Troczynski, and W.J. Tseng, Biomaterials. 22, 1721, (2001)

23. I. Rehman, and W. Bonfield, J Mater Sci-Mater M. 8, 1, (1997)

24. M. Vignoles, G. Bonel, D. Holcomb, et al, Calcified Tissue Int. 43, 33, (1988)

25. I.R. Gibson, and W. Bonfield, J Biomed Mater Res A. 59, 697, (2002) 